\title{
Multicentre analysis of hyperglycaemic hyperosmolar state and diabetic ketoacidosis in type 1 and type 2 diabetes
}

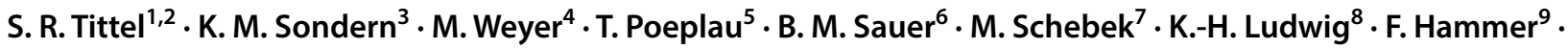 \\ E. Fröhlich-Reiterer ${ }^{10} \cdot$ R. W. Holl ${ }^{1,2} \cdot$ for the DPV Initiative
}

Received: 12 December 2019 / Accepted: 18 April 2020 / Published online: 2 June 2020

(c) The Author(s) 2020

\begin{abstract}
Aims To compare diabetes patients with hyperglycaemic hyperosmolar state (HHS), diabetic ketoacidosis (DKA), and patients without decompensation (ND).

Methods In total, 500,973 patients with type 1 or type 2 diabetes of all ages registered in the diabetes patient follow-up (DPV) were included. Analysis was stratified by age $(\leq />20$ years) and by manifestation/follow-up. Patients were categorized into three groups: HHS or DKA—during follow-up according to the most recent episode—or ND.

Results At onset of diabetes, HHS criteria were met by 345 (68.4\% T1D) and DKA by 9824 (97.6\% T1D) patients. DKA patients had a lower BMI(-SDS) in both diabetes types compared to ND. HbA1c was higher in HHS/DKA. During follow-up, HHS occurred in 1451 (42.2\% T1D) and DKA in 8389 patients (76.7\% T1D). In paediatric T1D, HHS/DKA was associated with younger age, depression, and dyslipidemia. Pump usage was less frequent in DKA patients. In adult T1D/T2D subjects, metabolic control was worse in patients with HHS/DKA. HHS and DKA were also associated with excessive alcohol intake, dementia, stroke, chronic kidney disease, and depression.

Conclusions HHS/DKA occurred mostly in T1D and younger patients. However, both also occurred in T2D, which is of great importance in the treatment of diabetes. Better education programmes are necessary to prevent decompensation and comorbidities.
\end{abstract}

Keywords Hyperglycaemic hyperosmolar state $\cdot$ Diabetic ketoacidosis $\cdot$ Acute complication $\cdot$ Metabolic decompensation · Multicentre registry

\section{Introduction}

Hyperglycaemic hyperosmolar state (HHS) and diabetic ketoacidosis (DKA) are life-threatening events for diabetes patients. According to the ISPAD guidelines [1], criteria for HHS include (1) plasma glucose concentration $>33.3 \mathrm{mmol} / \mathrm{l}$, (2) arterial $\mathrm{pH} \geq 7.3$, (3) serum bicarbonate $\geq 15 \mathrm{mmol} / \mathrm{l}$, (4) serum osmolality $>320 \mathrm{mOsm} / \mathrm{kg}$, (5) decreased consciousness or seizures, (6) absent or mild

\section{Managed by Massimo Federici.}

Electronic supplementary material The online version of this article (https://doi.org/10.1007/s00592-020-01538-0) contains supplementary material, which is available to authorized users.

S. R. Tittel

sascha.tittel@uni-ulm.de

Extended author information available on the last page of the article ketonuria, (7) absent to mild ketonemia; criteria for DKA are (1) blood glucose concentration $>11 \mathrm{mmol} / \mathrm{l}$, (2) $\mathrm{pH}<7.3$ and/or bicarbonate $<15 \mathrm{mmol} / \mathrm{l}$, (3) ketonemia or moderate to large ketonuria.

HHS is found more frequently in type 2 diabetes (T2D) and occurs in $2 \%$ of adolescents at manifestation [2]. However, HHS can also be present in type 1 diabetes (T1D). A common symptom of T1D manifestation is polydipsia, which leads to an increased ingestion of (high sugar) beverages. The high sugar content increases blood glucose and serum osmolality, promoting an HHS, in spite of T1D pathophysiology [3]. Polydipsia may go unnoticed first, so that an HHS develops relatively slow. However, untreated HHS leads to death [1]. Mortality ranges from 5 to $20 \%$, which is about 10 times higher compared with DKA, due to higher age or delayed diagnosis [4-6]. Previous studies reported higher occurrence of HHS in females and older patients $(60+$ years $)$ and at diabetes onset [7-9]. The most common 
risk factor for HHS is infection, followed by neurological sequelae, as well as myocardial infarction which may lead to severe dehydration $[8,10]$.

DKA is more common in T1D, and the percentage of DKA at manifestation ranges from 15 to $70 \%[5,11-13]$. It also occurs in T2D with pronounced insulin deficiency ("ketosis-prone diabetes") [5, 14]. DKA mortality varies between $<1$ and $>5 \%$ depending on age and comorbidities $[1,5,6]$ and is one of the main causes of death in adolescent T1D patients [11]. DKA is often the result of diagnostic errors and delayed treatment [1]. Risk factors are poor blood glucose control, excessive alcohol intake, depression, eating disorders, insulin pump use in T1D patients due to infusion site complications, patient errors, or pump device malfunction $[1,6,7,9,11,15-17]$. However, pump therapy was previously associated with lower DKA rates than injection therapy in paediatric patients $[1,18]$.

Since most previous studies reporting on HHS have used small sample sizes, in this study the large DPV database was used to characterize patients with HHS, and to compare them to patients with DKA and to patients without decompensation.

\section{Materials and methods}

We included patients with T1D or T2D documented in the prospective diabetes patient follow-up registry (DPV). DPV is a multicentre initiative comprising 437 centres in Germany, Austria, Switzerland, and Luxembourg (March 2019) [18].

Patients were assigned to the groups HHS/DKA according to the most recent event or to the group without decompensation (control). We differentiated between decompensation at onset and decompensation during follow-up. In a sensitivity analysis, we excluded patients with both HHS and DKA during follow-up.

Bicarbonate and $\mathrm{pH}$ thresholds for the definitions of HHS and DKA are according to the ISPAD guidelines [1]. Our fasting/post-prandial blood glucose threshold for HHS was $>55.5 \mathrm{mmol} / \mathrm{mol}(>33.3 \mathrm{mmol} / \mathrm{mol}$, if impaired consciousness was documented). Missing $\mathrm{pH} /$ bicarbonate values were assumed to $b e \geq 7.3, \geq 15 \mathrm{mmol} / \mathrm{l}$, respectively, because these measurements are mostly taken in case of suspected decompensation. In case of HHS, we also allowed for diagnosis without $\mathrm{pH} / \mathrm{bicarbonate}$ values if the diagnosis was clearly stated.

For analysis of decompensation at diabetes diagnosis, data were aggregated \pm 10 days around diabetes diagnosis. For follow-up analysis, data of patients with HHS/DKA were aggregated \pm 6 months, decompensation-related items \pm 10 days around the most recent event. Data of patients without decompensation were aggregated in the patient's most recent treatment year. During the respective time period, the highest blood glucose and the lowest $\mathrm{pH}$ and bicarbonate values were selected. Other patient data were aggregated using medians.

Demographic data were age, diabetes duration, age at diabetes diagnosis, and sex. Outcomes of interest were BMI(-SDS), HbA1c, injection versus pump therapy for T1D, therapy for T2D (insulin only, insulin + oral antidiabetics (OADs), OADs only, lifestyle modification only). $\mathrm{HbA} 1 \mathrm{c}$ was standardized using the multiple of the mean according to the Diabetes Control and Complication Trial (DCCT) [19]. For patients $\leq 20$ years, reference data from the German Health Interview and Examination Survey for Children and Adolescents (KiGGS) were used to compute BMI-SDS (z-scores) [20]. Migration background was defined as patient and/or at least one parent born outside Germany/Austria/Switzerland/Luxembourg [17], and only used in patients $\leq 20$ years, since it is rarely documented in adult patients.

Dyslipidemia was diagnosed in case of at least one abnormal lipid value [21]. Excessive alcohol intake was defined by alcohol consumption $\geq 24 \mathrm{~g}$ (male) or $\geq 12 \mathrm{~g}$ (female) per day, or via diagnosis. Depression and dementia were defined by respective diagnosis and/or medical therapy. Excessive alcohol intake, depression, or dementia had to be documented at least once. Macrovascular complications included coronary heart disease (CHD), heart failure, atrial flutter, stroke, peripheral artery occlusive disease (PAOD). Microvascular complications included retinopathy and nephropathy. Microalbuminuria was defined by urine albumin excretion of $\geq 30 \mathrm{mg}$ per day; chronic kidney disease (CKD) was diagnosed if the glomerular filtration rate (estimated by MDRD formula) was below $60 \mathrm{ml} / \mathrm{min}$ (for adults only) [19], or in case of renal transplantation and/or dialysis. If data of eye examination, albumin excretion, or cholesterol measurement were missing, patients were excluded from the respective analysis. If other comorbidities were not documented, absence was assumed.

Until March 2019, 534,756 patients were documented in the DPV. Included were 500,973 patients [T1D: 129,912 ( $\leq 20$ years: 77,098); T2D: 371,061 ( $>20$ years: 369,219$)$ ]. Data at diabetes diagnosis were available from 98,945 patients, at follow-up from 473,278 patients.

We stratified the analysis for paediatric patients ( $\leq 20$ years) and adult patients ( $>20$ years). Categorizations of variables for regression were chosen such that the respective category groups were similar in size: age $\leq />13$ years (paediatric patients),$\leq />50$ years (adult T1D patients), $\leq />70$ years (adult T2D patients); diabetes duration $<3,3-6,>6$ years (paediatric patients), $</ \geq 20$ years (adult T1D patients), $</ \geq 10$ years (adult T2D patients); $\mathrm{BMI}<18.5,18.5$ to $<25,25$ to $<30,30-<35, \geq 35 \mathrm{~kg} / \mathrm{m}^{2}$; 
treatment year: $</ \geq 2012$; HbA1c: $\leq />7.2 \%$ (55 mmol/ $\mathrm{mol}$ ); insulin dose: $</ \geq 0.7 \mathrm{IU} / \mathrm{kg} /$ day.

Medians and interquartile ranges (IQRs) were presented for continuous variables and percentages for categorical variables. Wilcoxon's rank sum test was used for group comparisons of continuous variables and Chi-square test for categorical variables. Two-sided $p$ values (significance set at $<0.05$ ) were adjusted for multiple testing (Bonferroni-Holm). HHS/DKA rates were calculated using negative binomial regression models with individual time under risk as offset.

Linear models for BMI(-SDS) and HbA1c models were adjusted for sex, age, and in paediatric patients additionally for migration background and presented as means \pm standard error. During follow-up, additional adjustments for diabetes duration and treatment year were made. Odds ratios (ORs) with $95 \%$ confidence intervals (95\% CI) were calculated via logistic regression models for comorbidities and adjusted for sex, age, treatment year, $\mathrm{HbA} 1 \mathrm{c}$, and diabetes duration. For T1D, the logistic models were additionally adjusted for pump therapy and insulin dose/kg/day. For T2D, the models were additionally adjusted for BMI and diabetes therapy.

\section{Results}

\section{Diabetes diagnosis}

Of 55,156 T1D patients, 236 experienced HHS and 9584 DKA at diabetes diagnosis. Among 43,789 T2D patients, 109 experienced HHS and 240 DKA at diagnosis. Paediatric T2D patients and adult T1D patients with HHS/DKA at diagnosis are included in Table 1, but not further analysed due to small sample sizes. See Table 1 for demographics of the cohort at diagnosis additionally stratified by age group.

\section{Paediatric T1D patients at diabetes diagnosis}

HHS patients $(n=223)$ were younger than DKA patients $(n=9508)(p=0.03)$. HHS/DKA patients were also younger than patients in the control group $(p<0.001)$. DKA patients were more likely to be female compared with HHS $(p=0.03)$ and control $(p<0.001)$. Migration background was more frequent in DKA compared with HHS $(p=0.03)$ and control $(p<0.001)$ (Table 2).

The adjusted BMI-SDS differed between all three groups (HHS: $-0.51 \pm 0.08$, DKA: $-0.29 \pm 0.01$, control: $-0.20 \pm 0.01, p<0.001)$. Adjusted HbA1c values were higher in HHS $[11.9 \pm 0.2 \%(106.7 \pm 1.8 \mathrm{mmol} / \mathrm{mol})]$ and DKA $[11.9 \pm 0.0 \%(106.3 \pm 0.3 \mathrm{mmol} / \mathrm{mol})]$ compared to control $[10.9 \pm 0.0 \%(96.0 \pm 0.1 \mathrm{mmol} / \mathrm{mol}), p<0.001]$.

\section{Adult T2D patients at diabetes diagnosis}

There were no remarkable differences in age and sex distribution between HHS $(n=108)$, DKA $(n=217)$, and control group $(n=42,413)$. DKA patients had a lower adjusted BMI $\left(30.0 \pm 0.5 \mathrm{~kg} / \mathrm{m}^{2}\right)$ compared with control group patients $\left(31.2 \pm 0.0 \mathrm{~kg} / \mathrm{m}^{2}, p=0.04\right)$. Adjusted HbA1c differed between all three groups: HHS $[12.2 \pm 0.3 \%(109.7 \pm 2.9 \mathrm{mmol} / \mathrm{mol})]$, DKA $[9.2 \pm 0.2 \%(77.2 \pm 2.0 \mathrm{mmol} / \mathrm{mol})]$, control $[8.5 \pm 0.0 \%$ $(69.2 \pm 0.2 \mathrm{mmol} / \mathrm{mol}), p<0.001]$.

\section{Diabetes follow-up}

Of 125,376 T1D patients, 613 experienced HHS and 6437 DKA during follow-up. Among 347,902 T2D patients, 838 experienced HHS and 1952 DKA during follow-up. Paediatric T2D patients with HHS/DKA during follow-up were not further analysed due to small sample size. Table 3 shows
Table 1 Demographics of the study cohort at diabetes diagnosis; data are presented as median [interquartile range] or as \%; T1D: type 1 diabetes; T2D: type 2 diabetes

\begin{tabular}{|c|c|c|c|}
\hline & Total & $\leq 20$ years & $>20$ years \\
\hline Number of cases & 98,945 & 49,976 & 48,969 \\
\hline Age (years) & $18.2[9.7$ to 60.4$]$ & $9.8[6.1$ to 13.0$]$ & $60.6[48.7$ to 71.6$]$ \\
\hline Male sex $(\%)$ & 55.3 & 53.8 & 56.9 \\
\hline BMI $\left(\mathrm{kg} / \mathrm{m}^{2}\right)$ & 22.2 [16.7 to 29.4$]$ & $16.9[15.3$ to 19.4$]$ & 29.4 [25.6 to 33.9$]$ \\
\hline BMI-SDS & $0.7[-0.4$ to 1.7$]$ & $-0.2[-0.9$ to 0.6$]$ & $1.6[0.9$ to 2.1$]$ \\
\hline $\mathrm{HbA} 1 \mathrm{c}(\%)$ & 10.0 [7.6 to 11.9$]$ & 10.9 [9.4 to 12.7$]$ & 8.0 [6.4 to 10.7$]$ \\
\hline $\mathrm{HbA} 1 \mathrm{c}(\mathrm{mmol} / \mathrm{mol})$ & 85.8 [59.3 to 107.1$]$ & 96.0 [79.2 to 115.0$]$ & 63.7 [46.6 to 93.9] \\
\hline Blood glucose (mmol/l) & 17.3 [10.2 to 25.7$]$ & 22.8 [16.5 to 29.9] & $11.0[7.7$ to 16.4$]$ \\
\hline Insulin dose (IU/kg/day) & $0.6[0.4$ to 0.9$]$ & $0.7[0.5$ to 0.9$]$ & $0.4[0.2$ to 0.6$]$ \\
\hline Migration background (\%) & 10.3 & 19.0 & 1.4 \\
\hline T1D (\%) & 55.7 & 97.9 & 12.7 \\
\hline $\mathrm{T} 2 \mathrm{D}(\%)$ & 44.3 & 2.1 & 87.3 \\
\hline HHS at diagnosis (\%) & 0.3 & 0.4 & 0.2 \\
\hline DKA at diagnosis (\%) & 9.9 & 19.1 & 0.6 \\
\hline
\end{tabular}


Table 2 Characteristics of paediatric T1D and adult T2D patients at diagnosis; $p$ values adjusted for multiple testing; data are presented as median [interquartile range] or as $\%$

\begin{tabular}{|c|c|c|c|c|c|c|}
\hline & HHS & DKA & ND & $\begin{array}{l}p \text { values HHS } \\
\text { versus DKA }\end{array}$ & $\begin{array}{l}p \text { values HHS } \\
\text { versus ND }\end{array}$ & $\begin{array}{l}p \text { values } \\
\text { DKA versus } \\
\text { ND }\end{array}$ \\
\hline \multicolumn{7}{|l|}{ Paediatric T1D } \\
\hline Number of cases & 223 & 9508 & 39,194 & & & \\
\hline Age (years) & $7.5[3.8-11.9]$ & $9.5[4.9-12.5]$ & $9.7[6.2-12.9]$ & 0.03 & $<.001$ & $<.001$ \\
\hline Male sex $(\%)$ & 60.5 & 52.5 & 54.5 & 0.03 & .13 & $<.001$ \\
\hline Migration background (\%) & 17.0 & 24.5 & 17.4 & 0.03 & .89 & $<.001$ \\
\hline \multicolumn{7}{|l|}{ Adult $T 2 D$} \\
\hline Number of cases & 108 & 217 & 42,413 & & & \\
\hline Age (years) & $66.5[53.8-78.3]$ & $63.5[51.9-75.9]$ & $62.7[52.0-72.8]$ & .19 & .008 & .41 \\
\hline Male sex $(\%)$ & 55.6 & 60.4 & 56.8 & .41 & .80 & .41 \\
\hline
\end{tabular}

Table 3 Demographics of the study cohort during follow-up; data are presented as median [interquartile range] or as \%; T1D: type 1 diabetes; T2D: type 2 diabetes

\begin{tabular}{|c|c|c|c|}
\hline & Total & $\leq 20$ years & $>20$ years \\
\hline Number of cases & 473,278 & 76,764 & 396,514 \\
\hline Age (years) & 64.9 [45.5 to 75.9$]$ & $15.4[12.0$ to 17.4$]$ & $68.8[57.3$ to 77.5$]$ \\
\hline Age at diabetes onset (years) & 52.1 [31.1 to 64.5$]$ & $8.8[5.2$ to 12.1$]$ & $56.2[44.6$ to 66.6$]$ \\
\hline Male sex $(\%)$ & 52.5 & 52.6 & 52.5 \\
\hline BMI $\left(\mathrm{kg} / \mathrm{m}^{2}\right)$ & 27.8 [23.9 to 32.6$]$ & 21.3 [18.4 to 24.2$]$ & $29.1[25.5$ to 33.6$]$ \\
\hline BMI-SDS & $1.4[0.6$ to 2.0$]$ & $0.3[-0.3$ to 1.0$]$ & $1.5[0.9$ to 2.1$]$ \\
\hline $\mathrm{HbA} 1 \mathrm{c}(\%)$ & $7.3[6.4$ to 8.5$]$ & $7.8[7.0$ to 8.9$]$ & $7.2[6.3$ to 8.4$]$ \\
\hline $\mathrm{HbA} 1 \mathrm{c}(\mathrm{mmol} / \mathrm{mol})$ & 56.3 [46.6 to 69.7 ] & $61.9[52.9$ to 74.1$]$ & $54.9[45.5$ to 68.5$]$ \\
\hline Blood glucose (mmol/l) & $10.5[7.9$ to 14.2$]$ & $13.6[9.7$ to 18.2$]$ & $10.0[7.7$ to 13.5$]$ \\
\hline Insulin dose (IU/kg/day) & $0.6[0.4$ to 0.9$]$ & $0.8[0.7$ to 1.0$]$ & $0.5[0.3$ to 0.8$]$ \\
\hline Migration background (\%) & 4.3 & 18.3 & 1.6 \\
\hline T1D (\%) & 26.5 & 97.9 & 12.7 \\
\hline $\mathrm{T} 2 \mathrm{D}(\%)$ & 73.5 & 2.1 & 87.3 \\
\hline HHS during follow-up (\%) & 0.3 & 0.6 & 0.3 \\
\hline DKA during follow-up (\%) & 1.8 & 7.6 & 0.6 \\
\hline Pump therapy (\%) & 13.2 & 38.1 & 4.8 \\
\hline Insulin only (\%) & 43.9 & 94.0 & 34.2 \\
\hline OAD/GLPA only (\%) & 19.3 & 0.9 & 22.8 \\
\hline Insulin and OAD/GLPA (\%) & 17.2 & 1.1 & 20.3 \\
\hline Lifestyle only (\%) & 19.6 & 4.0 & 22.7 \\
\hline
\end{tabular}

patient demographics during follow-up additionally stratified by age group.

\section{Paediatric T1D patients during follow-up}

Patients with HHS $(n=443)$ and patients with DKA $(n=5843)$ were younger than control patients $(n=68,866$, $p=0.03, p<0.001$, respectively) (Table 4 ). The proportion of males was higher in the control group compared to DKA $(p<0.001)$. Patients with DKA were less frequently treated with pump compared to HHS $(p=0.004)$ and control $(p<0.001)$ patients. Adjusting for age, sex, diabetes duration, and migration background did not change the outcome.

Patients with DKA were leaner (adjusted BMI-SDS: $0.18 \pm 0.01)$ compared with control $(0.31 \pm 0.00, p<0.001)$ and HHS $(0.27 \pm 0.04, p=0.03)$, but had a higher adjusted HbA1c than both other groups [DKA: $9.5 \pm 0.0 \%$ $(79.9 \pm 0.2 \mathrm{mmol} / \mathrm{mol})$; HHS: $8.1 \pm 0.1 \%(64.4 \pm 0.8 \mathrm{mmol} /$ mol); control: $8.0 \pm 0.0 \%(64.4 \pm 0.1 \mathrm{mmol} / \mathrm{mol})]$.

Dyslipidemia and depression were related to HHS and DKA (Supplementary Fig. 1a, b). All models were adjusted for demographics, treatment, and treatment year. 
Table 4 Characteristics of paediatric T1D, adult T1D and adult T2D patients during follow-up; $p$ values adjusted for multiple testing; data are presented as median [interquartile range] or as \%

\begin{tabular}{|c|c|c|c|c|c|c|}
\hline & HHS & DKA & ND & $\begin{array}{l}p \text { values HHS } \\
\text { versus DKA }\end{array}$ & $\begin{array}{l}p \text { values HHS } \\
\text { versus ND }\end{array}$ & $\begin{array}{l}p \text { values } \\
\text { DKA versus } \\
\text { ND }\end{array}$ \\
\hline \multicolumn{7}{|l|}{ Paediatric T1D } \\
\hline Number of cases & 443 & 5843 & 68,866 & & & \\
\hline Age (years) & $13.4[10.0-16.0]$ & $14.0[11.5-16.1]$ & $15.6[12.0-17.5]$ & .03 & $<.001$ & $<.001$ \\
\hline Age at diabetes onset (years) & $7.9[4.9-11.0]$ & $7.9[4.6-10.8]$ & $8.8[5.1-12.1]$ & 1.00 & .003 & $<.001$ \\
\hline Male sex $(\%)$ & 47.6 & 47.4 & 53.5 & 1.00 & .06 & $<.001$ \\
\hline Migration background (\%) & 21.9 & 21.7 & 17.7 & 1.00 & .07 & $<.001$ \\
\hline Pump therapy (\%) & 43.8 & 35.7 & 38.6 & .004 & .067 & $<.001$ \\
\hline \multicolumn{7}{|l|}{ Adult T1D } \\
\hline Number of cases & 170 & 594 & 49,460 & & & \\
\hline Age (years) & $49.7[35.5-67.5]$ & $42.0[27.0-56.8]$ & $44.8[30.1-59.0]$ & $<.001$ & .001 & .02 \\
\hline Age at diabetes onset (years) & $26.0[14.8-41.2]$ & $22.0[12.6-33.1]$ & $24.6[13.1-38.3]$ & $<.001$ & .30 & $<.001$ \\
\hline Male sex (\%) & 48.8 & 49.7 & 52.6 & .85 & .33 & .23 \\
\hline Pump therapy (\%) & 16.1 & 22.4 & 25.9 & .25 & .02 & .23 \\
\hline \multicolumn{7}{|l|}{ Adult $T 2 D$} \\
\hline Number of cases & 834 & 1938 & 343,518 & & & \\
\hline Age (years) & $72.3[63.4-79.3]$ & $73.0[63.7-80.0]$ & $70.6[60.8-78.3]$ & .83 & $<.001$ & $<.001$ \\
\hline Age at diabetes onset (years) & 60.9 [51.9-69.9] & $59.9[49.7-69.7]$ & $58.5[48.8-67.9]$ & .32 & $<.001$ & $<.001$ \\
\hline Male sex $(\%)$ & 52.2 & 50.1 & 52.5 & .83 & 1.00 & .06 \\
\hline Insulin only (\%) & 36.6 & 45.6 & 28.8 & $<.001$ & $<.001$ & $<.001$ \\
\hline OAD/GLPA only (\%) & 20.5 & 18.7 & 26.0 & .83 & $<.001$ & $<.001$ \\
\hline Insulin and OAD/GLPA (\%) & 32.0 & 21.9 & 22.6 & $<.001$ & $<.001$ & .47 \\
\hline Lifestyle only (\%) & 10.9 & 13.7 & 22.7 & .21 & $<.001$ & $<.001$ \\
\hline SGLT2 inhibitor medication (\%) & 3.6 & 1.7 & 2.6 & .01 & .22 & .04 \\
\hline
\end{tabular}

\section{Adult T1D patients during follow-up}

HHS patients $(n=170)$ were older compared to DKA $(n=594, p<0.001)$ and control patients $(n=49,460$, $p<0.001$, Table 4$)$. DKA patients were younger at diabetes diagnosis compared with HHS $(p=0.01)$ and control $(p<0.001)$. Injection therapy was more frequent in HHS compared with control $(\mathrm{p}=0.02)$.

The adjusted BMI was lower in DKA $\left(24.2 \pm 0.2 \mathrm{~kg} / \mathrm{m}^{2}\right.$, $p<0.001)$ and HHS $\left(25.0 \pm 0.4 \mathrm{~kg} / \mathrm{m}^{2}, p=0.049\right)$ compared with control $\left(26.0 \pm 0.0 \mathrm{~kg} / \mathrm{m}^{2}\right)$. However, adjusted $\mathrm{HbA} 1 \mathrm{c}$ was higher in both HHS $[8.9 \pm 0.1 \%(73.6 \pm 1.6 \mathrm{mmol} / \mathrm{mol})]$ and DKA $[9.6 \pm 0.1 \%(81.7 \pm 0.8 \mathrm{mmol} / \mathrm{mol}))$ compared with control $(7.9 \pm 0.0 \%(63.3 \pm 0.1 \mathrm{mmol} / \mathrm{mol})]$.

Adjusted regression models showed positive associations of dyslipidemia, excessive alcohol intake, depression, dementia, PAOD, and CKD with HHS and DKA (Supplementary Fig. 1c, d).

\section{Adult T2D patients during follow-up}

Patients with HHS $(n=834)$ and patients with DKA $(n=1938)$ were older than control $(n=343,518, p<0.001$, Table 4). There were differences in diabetes therapy regimen between all groups. Use of SGLT2 inhibitors was less frequent in DKA compared to HHS and control.

There were differences in adjusted $\mathrm{HbA1} \mathrm{c}$ between all three groups [HHS: $8.5 \pm 0.1 \%(69.2 \pm 0.7 \mathrm{mmol} / \mathrm{mol})$, DKA: $7.7 \pm 0.0 \%(60.7 \pm 0.5 \mathrm{mmol} / \mathrm{mol})$, control: $7.5 \pm 0.0 \%$ $(58.8 \pm 0.0 \mathrm{mmol} / \mathrm{mol}), p<0.001]$.

We found associations between HHS/DKA and excessive alcohol intake, depression, dementia, CHD, stroke, and CKD (Supplementary Fig. 1e, f). DKA was also associated with retinopathy. There was also an inverse association between DKA and dyslipidemia. 


\section{Sensitivity analysis}

Excluding patients that experienced both HHS and DKA during follow-up $(n=91)$, we could not detect significant changes in outcome in any group.

\section{Discussion}

Describing and comparing patients with HHS, DKA, and non-decompensation at diagnosis and during follow-up in a large diabetes cohort, we found treatment and metabolic control differences, as well as associations between decompensation and several comorbidities. Both DKA and HHS occurred more often in paediatric T1D patients at diagnosis and during follow-up.

Among all subjects with HHS, $19.2 \%$ were not previously diagnosed with diabetes which is comparable with previous findings [8]. DKA at diagnosis was present in almost every fifth paediatric patient with T1D, also comparable with previous results [5]. Among T2D patients, DKA frequencies at diagnosis ranged from $0.5 \%$ in adults to $2.2 \%$ in paediatric patients, which is far less than previous reports of $6-11 \%[1,2]$. Different results might derive from different definitions of HHS and DKA, different inclusion criteria, or size of study population. Our main findings are in line with previous findings.

Among the paediatric T1D group, patients with decompensation at diagnosis were younger compared to the control group. Diabetes manifestation in younger children may be misdiagnosed when presenting at the doctor's office as having pneumonia or asthma, even worsening the condition by inappropriate treatment, possibly leading to serious long-term effects or death [12, 22, 23].

Among the paediatric T1D group patients with decompensation during follow-up were younger compared to patients in the control group. Parents may lay diabetesrelated responsibility on their children too soon, resulting in poor therapy adherence amongst other things [24]. Female sex was more frequent in the DKA group compared with the control group. Female sex has been described as a risk factor for DKA [9, 25], especially in adolescent girls who try to lose weight by omitting insulin [1]. This is confirmed by our findings of a lower BMISDS and poorer metabolic control in patients of both sexes with DKA. Moreover, migration background, which was analysed in paediatric T1D patients only due to lack of documentation in older patients, was more common in patients with DKA. Frequency of pump therapy was lower in patients with DKA. Previous studies found that migration background and lower socioeconomic status (SES) are associated with lower frequency of insulin pump therapy, higher BMI, worse metabolic control, and DKA [26-28].
Low SES and/or migration background may act as confounders to the frequency of pump use. However, adjusting for migration background in paediatric T1D patients did not change the lower frequency of pump use in DKA patients. Furthermore, insulin pumps have been associated with DKA due to unrecognized interruption of insulin delivery [1]. On the other hand, pump use has also been described to be rather protective against DKA [18], which is confirmed by a lower pump usage in patients with DKA in our study.

Among adult T2D patients, HHS at diagnosis was associated with older age compared with control [29]. Older patients may not recognize diabetes symptoms, similar to younger children. Patients with decompensation had a higher $\mathrm{HbA} 1 \mathrm{c}$ compared with control, hinting at more severe diabetes manifestation with elevated blood glucose over a longer time span before diagnosis.

Adult T1D or T2D patients with HHS during follow-up were older. One reason might be reduced fluid intake of older patients [30] or the fact that older people often have more comorbidities [31], which makes diabetes treatment more complicated, especially during sick days $[8,10]$. T2D patients with a more severe diabetes are more likely to be treated with insulin [32], and more severe diabetes can lead to decompensation. Old age is associated with HHS in adult T2D, which is also associated with infection [8]. SGLT2 inhibitors, despite their beneficial effects on blood glucose, blood pressure, and CVD risk [33, 34], may induce euglycaemic DKA, even doubling the risk compared with DPP4 inhibitors [5, 35], which is an important factor considering the occurrence of DKA in T2D. Some argue that the benefits outweigh the low rate of adverse events [34]. The lower frequency of SGLT2 inhibitor treatment in DKA patients may result from informed doctors not prescribing SGLT2 inhibitors to patients with high risk/history of DKA.

Higher HbAlc levels in patients with decompensation were found in all four groups. Elevated $\mathrm{HbA} 1 \mathrm{c}$ might derive from a more severe manifestation of diabetes, or is more difficult to adjust during follow-up, from poor therapy adherence, or other causes. Since HHS develops slowly, higher blood glucose levels over a prolonged time span are probable, leading to an elevated HbA1c [36]. In adolescents, higher $\mathrm{HbA} 1 \mathrm{c}$ levels could also be related to deliberate insulin omission in combination with the aforementioned lower BMI-SDS. However, lower BMI and higher HbA1c were also found in adult patients with decompensation.

Depression was related to decompensation, possibly due to forgetting or inability to take insulin or due to injection of an incorrect dose [6, 9, 11, 16, 17, 37, 38]. Excessive alcohol intake was associated with HHS/DKA, reinforcing findings of administering insulin incorrectly under the influence of alcohol $[6,9,11]$. Patients with excessive alcohol intake could also experience DKA due to vomiting from alcohol 
intoxication. Alcohol consumption should be addressed in patient education for adolescents.

Results from a German study have shown that screening and close supervision of high-risk patients (familiar T1D, single-nucleotide polymorphisms) could prevent DKA at manifestation of clinical T1D [39]. After onset of diabetes, better education, especially regarding metabolic decompensation, can lead to better diabetes self-management [40] and prevent stress caused by diabetes [41], ideally resulting in a better acceptance of the chronic condition and lower rates of decompensation.

The major strengths of this study include the large number of patients with HHS/DKA available for analysis due to the size of the database, and the distribution of centres throughout different European countries. Weaknesses typical for observational studies are the amount of missing data, especially laboratory data, that could help identify patients with HHS/DKA, and the impossibility of detecting causal effects between comorbidities and outcome. Furthermore, there may be patients with HHS and light acidosis, as well as DKA with a very high blood glucose maybe due to ingestions of very sugary beverages, which we did not account for, since we chose mutually exclusive group definitions. The classic concept of ethnicity as in the USA could not be used as a covariate, since in Germany most people including immigrants are Caucasian. Therefore, it is difficult to standardize this concept, and we relied on migration background as approach for ethnic minorities. Since DKA in T2D is atypical, adult T2D patients with DKA may actually have LADA (late onset autoimmune diabetes in the adult), which is now considered a subgroup of T1D [42]. Having only few patients with DKA and beta-cell antibody measurement in adult T2D patients, we could not investigate whether they had LADA or not. Since there is no reliable biomarker for T1D/T2D, there may be some initial misclassifications. Over the last 20 years, $1.7 \%$ of patients changed their documented diabetes type in our cohort. Therefore, the percentages of HHS/DKA by diabetes type may vary only slightly.

\section{Conclusion}

HHS/DKA are associated with health risks in both, paediatric and adult, T1D and T2D patients, at diagnosis and during follow-up. Decompensations are associated with possibly preventable comorbidities. Better and more accessible education programmes are needed, especially for risk groups such as adolescents and the elderly.
Acknowledgements Open Access funding provided by Projekt DEAL. We wish to thank all centres participating in the DPV project. For a full list of participating DPV centres, see the supplement. Special thanks to A. Hungele and R. Ranz for development of the DPV documentation software and K. Fink and E. Bollow for the DPV data management (clinical data managers, Ulm University). This work was supported by the German Centre of Diabetes Research (DZD) funded by the Federal Ministry of Education and Research (FKZ 82DZD0017G). Further financial support for the DPV registry was provided by the German Diabetes Association (DDG), the Robert Koch Institute (RKI), and by the European Foundation for the Study of Diabetes (EFSD).

\section{Compliance with ethical standards}

Conflict of interest The authors declare that there is no conflict of interest.

Ethical standard statement The registry was conducted in accordance with Good Epidemiology Practice and applicable regulatory requirements. The protocol of DPV was approved by the ethics committee of Ulm University (approval no. 202/09), and data collection was approved by local review board.

Human and animal rights All procedures performed in studies involving human participants were in accordance with the ethical standards of the national research committee and with the 1964 Helsinki declaration and its later amendments or comparable ethical standards.

Informed consent All patients being enrolled into this registry provided written informed consent.

Open Access This article is licensed under a Creative Commons Attribution 4.0 International License, which permits use, sharing, adaptation, distribution and reproduction in any medium or format, as long as you give appropriate credit to the original author(s) and the source, provide a link to the Creative Commons licence, and indicate if changes were made. The images or other third party material in this article are included in the article's Creative Commons licence, unless indicated otherwise in a credit line to the material. If material is not included in the article's Creative Commons licence and your intended use is not permitted by statutory regulation or exceeds the permitted use, you will need to obtain permission directly from the copyright holder. To view a copy of this licence, visit http://creativecommons.org/licenses/by/4.0/.

\section{References}

1. Wolfsdorf JI, Glaser N, Agus M et al (2018) ISPAD clinical practice consensus guidelines 2018: diabetic ketoacidosis and the hyperglycemic hyperosmolar state. Pediatr Diabetes 19(Suppl 27):155-177. https://doi.org/10.1111/pedi.12701

2. Klingensmith GJ, Connor CG, Ruedy KJ et al (2016) Presentation of youth with type 2 diabetes in the pediatric diabetes consortium. Pediatr Diabetes 17:266-273. https://doi.org/10.1111/pedi.12281

3. Watanabe S, Kido J, Ogata M, Nakamura K, Mizukami T (2019) Hyperglycemic hyperosmolar state in an adolescent with type 1 diabetes mellitus. Endocrinol Diabetes Metab Case Rep 2019:1-4. https://doi.org/10.1530/EDM-18-0131 
4. Price A, Losek J, Jackson B (2016) Hyperglycaemic hyperosmolar syndrome in children: patient characteristics, diagnostic delays and associated complications. J Paediatr Child Health 52:80-84. https://doi.org/10.1111/jpc. 12980

5. Kalscheuer H, Serfling G, Schmid S, Lehnert H (2017) Diabetic emergencies : hypoglycemia, ketoacidotic and hyperglycemic hyperosmolar nonketotic coma. Internist (Berl) 58:1020-1028. https://doi.org/10.1007/s00108-017-0317-x

6. Bradford AL, Crider CC, Xu X, Naqvi SH (2017) Predictors of recurrent hospital admission for patients presenting with diabetic ketoacidosis and hyperglycemic hyperosmolar state. J Clin Med Res 9:35-39. https://doi.org/10.14740/jocmr2792w

7. Umpierrez G, Korytkowski M (2016) Diabetic emergenciesketoacidosis, hyperglycaemic hyperosmolar state and hypoglycaemia. Nat Rev Endocrinol 12:222-232. https://doi.org/10.1038/ nrendo.2016.15

8. Misra UK, Kalita J, Bhoi SK, Dubey D (2017) Spectrum of hyperosmolar hyperglycaemic state in neurology practice. Indian J Med Res 146:S1-S7. https://doi.org/10.4103/ijmr.IJMR_57_15

9. Hermann JM, Meusers M, Bachran R et al (2017) Self-reported regular alcohol consumption in adolescents and emerging adults with type 1 diabetes: a neglected risk factor for diabetic ketoacidosis? Multicenter analysis of 29630 patients from the DPV registry. Pediatr Diabetes 18:817-823. https://doi.org/10.1111/pedi.12496

10. Pasquel FJ, Umpierrez GE (2014) Hyperosmolar hyperglycemic state: a historic review of the clinical presentation, diagnosis, and treatment. Diabetes Care 37:3124-3131. https://doi.org/10.2337/ dc14-0984

11. Randall L, Begovic J, Hudson M et al (2011) Recurrent diabetic ketoacidosis in inner-city minority patients: behavioral, socioeconomic, and psychosocial factors. Diabetes Care 34:1891-1896. https://doi.org/10.2337/dc11-0701

12. Wolfsdorf J, Glaser N, Sperling MA (2006) Diabetic ketoacidosis in infants, children, and adolescents: a consensus statement from the American Diabetes Association. Diabetes Care 29:1150-1159. https://doi.org/10.2337/diacare.2951150

13. Quinn M, Fleischman A, Rosner B, Nigrin DJ, Wolfsdorf JI (2006) Characteristics at diagnosis of type 1 diabetes in children younger than 6 years. J Pediatr 148:366-371. https://doi.org/10.1016/j. jpeds.2005.10.029

14. Newton CA, Raskin P (2004) Diabetic ketoacidosis in type 1 and type 2 diabetes mellitus: clinical and biochemical differences. Arch Intern Med 164:1925-1931. https://doi.org/10.1001/archi nte.164.17.1925

15. Giessmann LC, Kann PH (2018) Risk and relevance of insulin pump therapy in the aetiology of ketoacidosis in people with type 1 diabetes. Exp Clin Endocrinol Diabetes. https://doi. org/10.1055/a-0654-5134

16. Galler A, Bollow E, Meusers M et al (2015) Comparison of glycemic and metabolic control in youth with type 1 diabetes with and without antipsychotic medication: analysis from the nationwide German/Austrian Diabetes Survey (DPV). Diabetes Care 38:1051-1057. https://doi.org/10.2337/dc14-2538

17. Reinehr T, Dieris B, Galler A et al (2019) Worse metabolic control and dynamics of weight status in adolescent girls point to eating disorders in the first years after manifestation of type 1 diabetes mellitus: findings from the diabetes patienten Verlaufsdokumentation Registry. J Pediatr 207:205-212.e5. https://doi.org/10.1016/j. jpeds.2018.11.037

18. Karges B, Schwandt A, Heidtmann B et al (2017) Association of insulin pump therapy vs insulin injection therapy with severe hypoglycemia, ketoacidosis, and glycemic control among children, adolescents, and young adults with type 1 diabetes. JAMA 318:1358-1366. https://doi.org/10.1001/jama.2017.13994
19. Bohn B, Grünerbel A, Altmeier M et al (2018) Diabetic foot syndrome in patients with diabetes. A multicenter German/Austrian DPV analysis on 33870 patients. Diabetes Metab. Res. Rev. 34:e3020. https://doi.org/10.1002/dmrr.3020

20. Rosario AS, Kurth B, Stolzenberg H, Ellert U, Neuhauser H (2010) Body mass index percentiles for children and adolescents in Germany based on a nationally representative sample (KiGGS 2003-2006). Eur J Clin Nutr 64:341-349. https://doi.org/10.1038/ ejcn.2010.8

21. Hayman LL, Meininger JC, Daniels SR et al (2007) Primary prevention of cardiovascular disease in nursing practice: focus on children and youth: a scientific statement from the American Heart Association Committee on Atherosclerosis, Hypertension, and Obesity in Youth of the Council on Cardiovascular Disease in the Young, Council on Cardiovascular Nursing, Council on Epidemiology and Prevention, and Council on Nutrition, Physical Activity, and Metabolism. Circulation 116:344-357. https://doi. org/10.1161/CIRCULATIONAHA.107.184595

22. Kear C, Fisher T, Westwood E, Sachdev P, Denvir L (2016) G194(P) delayed diagnosis of type 1 diabetes mellitus (T1DM) in children. Arch Dis Child 101:A103-A104. https://doi. org/10.1136/archdischild-2016-310863.185

23. Narendran $P$ (2019) Screening for type 1 diabetes: are we nearly there yet? Diabetologia 62:24-27. https://doi.org/10.1007/s0012 5-018-4774-0

24. Harris MA, Mertlich D, Rothweiler J (2001) Parenting children with diabetes. Diabetes Spectrum 14:182-184. https://doi. org/10.2337/diaspect.14.4.182

25. Fadini GP, de Kreutzenberg SV, Rigato M et al (2011) Characteristics and outcomes of the hyperglycemic hyperosmolar non-ketotic syndrome in a cohort of 51 consecutive cases at a single center. Diabetes Res Clin Pract 94:172-179. https://doi. org/10.1016/j.diabres.2011.06.018

26. Scheuing N, Wiegand S, Bächle C et al (2015) Impact of maternal country of birth on type-1-diabetes therapy and outcome in 27,643 children and adolescents from the DPV registry. PLoS ONE 10:e0135178. https://doi.org/10.1371/journal.pone.0135178

27. Auzanneau M, Lanzinger S, Bohn B et al (2018) Area deprivation and regional disparities in treatment and outcome quality of 29,284 pediatric patients with type 1 diabetes in Germany: a cross-sectional multicenter DPV analysis. Diabetes Care 41:25172525. https://doi.org/10.2337/dc18-0724

28. Al-Obaidi A, Alidrisi H, Mansour A (2019) Precipitating factors for diabetic ketoacidosis among patients with type 1 diabetes mellitus: the effect of socioeconomic status. Int J Diabetes Metab 25:52-60. https://doi.org/10.1159/000499839

29. Kruljac I, Ćaćić M, Ćaćić P et al (2018) The impact of hyperosmolarity on long-term outcome in patients presenting with severe hyperglycemic crisis: a population based study. Exp Clin Endocrinol Diabetes 126:564-569. https://doi. org/10.1055/s-0043-117416

30. Kenney WL, Chiu P (2001) Influence of age on thirst and fluid intake. Med Sci Sports Exerc 33:1524-1532

31. Jaul E, Barron J (2017) Age-related diseases and clinical and public health implications for the 85 years old and over population. Front Public Health 5:335. https://doi.org/10.3389/fpubh .2017 .00335

32. Swinnen SG, Hoekstra JB, DeVries JH (2009) Insulin therapy for type 2 diabetes. Diabetes Care 32:S253-S259. https://doi. org/10.2337/dc09-S318

33. Goldenberg RM, Berard LD, Cheng AYY et al (2016) SGLT2 inhibitor-associated diabetic ketoacidosis: clinical review and recommendations for prevention and diagnosis. Clin Ther 38:26542664.e1. https://doi.org/10.1016/j.clinthera.2016.11.002 
34. Garcia-Ropero A, Badimon JJ, Santos-Gallego CG (2018) The pharmacokinetics and pharmacodynamics of SGLT2 inhibitors for type 2 diabetes mellitus: the latest developments. Expert Opin Drug Metab Toxicol 14:1287-1302. https://doi.org/10.1080/17425 255.2018.1551877

35. Karakaya Z, Topal FE, Topal F, Payza U, Akyol PY (2018) Euglisemic diabetic ketoacidotic coma caused by dapagliflozin. Am J Emerg Med 36(2136):e1-2136.e2. https://doi.org/10.1016/j. ajem.2018.08.054

36. Chiasson J, Aris-Jilwan N, Bélanger R et al (2003) Diagnosis and treatment of diabetic ketoacidosis and the hyperglycemic hyperosmolar state. CMAJ 168:859-866

37. Vuk A, Kuzman MR, Baretic M, Osvatic MM (2017) Diabetic ketoacidosis associated with antipsychotic drugs: case reports and a review of literature. Psychiatr Danub 29:121-135

38. Hilgard D, Konrad K, Meusers M et al (2017) Comorbidity of attention deficit hyperactivity disorder and type 1 diabetes in children and adolescents: analysis based on the multicentre DPV registry. Pediatr Diabetes 18:706-713. https://doi.org/10.1111/ pedi. 12431

39. Hommel A, Haupt F, Delivani P et al (2018) Screening for type 1 diabetes risk in newborns: the Freder1k pilot study in Saxony.
Horm Metab Res 50:44-49. https://doi.org/10.1055/s-0043-12092 1

40. Lamprinos I, Demski H, Mantwill S, Kabak Y, Hildebrand C, Ploessnig M (2016) Modular ICT-based patient empowerment framework for self-management of diabetes: design perspectives and validation results. Int J Med Inform 91:31-43. https://doi. org/10.1016/j.ijmedinf.2016.04.006

41. Hermanns N, Kulzer B, Maier B, Mahr M, Haak T (2012) The effect of an education programme (MEDIAS 2 ICT) involving intensive insulin treatment for people with type 2 diabetes. Patient Educ Couns 86:226-232. https://doi.org/10.1016/j. pec.2011.05.017

42. Pozzilli P, Pieralice S (2018) Latent autoimmune diabetes in adults: current status and new horizons. Endocrinol Metab (Seoul) 33:147-159. https://doi.org/10.3803/EnM.2018.33.2.147

Publisher's Note Springer Nature remains neutral with regard to jurisdictional claims in published maps and institutional affiliations.

\section{Affiliations}

\section{S. R. Tittel ${ }^{1,2} \cdot$ K. M. Sondern ${ }^{3} \cdot$ M. Weyer ${ }^{4} \cdot$ T. Poeplau ${ }^{5} \cdot$ B. M. Sauer ${ }^{6} \cdot$ M. Schebek ${ }^{7} \cdot$ K.-H. Ludwig ${ }^{8} \cdot$ F. Hammer ${ }^{9}$.

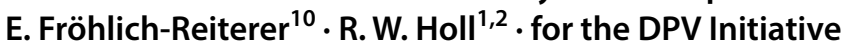

1 Institute of Epidemiology and Medical Biometry, Central Institute for Biomedical Technology (ZIBMT), Ulm University, Albert-Einstein-Allee 41, 89081 Ulm, Germany

2 German Centre for Diabetes Research (DZD), Munich-Neuherberg, Germany

3 Marien Hospital, Dortmund-Hombruch, Germany

4 Kamillus-Klinik Internal Medicine, Asbach, Germany

5 Clemenshospital, Ludgerus-Kliniken GmbH, Münster, Germany

6 Medical Clinic Internal Medicine, Spaichingen, Germany
7 Paediatric Clinic, Kassel, Germany

8 Paediatric Clinic of the Borromeans, Trier, Germany

9 Cnopf Children's Clinic, Nuremberg, Germany

10 Department of Paediatrics, Medical University Graz, Graz, Austria 